\title{
COMPARATIVE STUdy OF METHODS For OPTIMAL Reactive Power Dispatch
}

\author{
Tejaswini Sharma ${ }^{1}$, Alka Yadav $^{2}$, Sangeeta Jamhoria $^{3}$ and Ritu Chaturvedi ${ }^{4}$ \\ 1, 2,3,4 Department of Electrical Engineering, Madhav Institute of Technology \& Science \\ Gwalior, India
}

\begin{abstract}
Reactive power dispatch plays a main role in order to provide good facility secure and economic operation in the power system. In a power system optimal reactive power dispatch is supported to improve the voltage profile, to reduce losses, to improve voltage stability, to reduce cost etc. This paper presents a brief literature survey of reactive power dispatch and also discusses a comparative study of conventional and evolutionary computation techniques applied for reactive power dispatch. The paper is useful for researchers for further research and study so that it can apply in the various areas of power system.
\end{abstract}

\section{KEYWORDS}

Optimal Reactive Power Dispatch, Conventional Techniques, Evolutionary Computation Techniques.

\section{INTRODUCTION}

Optimal power flow (OPF) is a main concern in the power systems. This problem can be divided into problems, real power and reactive power dispatch is a sub problem of OPF[1]. Optimal Reactive power dispatch is a crucial task for both planning and operations of power systems [2]. Transformer and transmission lines introduce inductance as well as resistance and both transformer and transmission lines oppose the flow of the current [3].

Throughout the decades, research on reactive power has been going on. The problem of reactive power dispatch for improving economic operation and control of power system has arriving much more attention [4]. To regulate the power system voltage stability, voltage profile and to reduce the power loss appropriate reactive power and voltage are required $[5,6]$. The control variables of ORPD are namely, generator voltage magnitude, the tap ratios of transformer, static VAR sources; etc. The constraints contain the voltage limits of buses, tap ratio limits, VAR voltage limits of generators, VAR source limits etc. Sources of Reactive Power are two types namely: static and dynamics. Static reactive power sources are Shunt Capacitors, Filter banks, Underground cables, Transmission lines, Fuel cells, PV systems. Dynamic reactive power sources are FACTS devices, Synchronous Condensers, Synchronous Generators $[1,3,6]$.

There are so many approaches have been proposed for optimal reactive power dispatch in a power system over the past decades. Conventional techniques like Mixed integer Programming, Predictor Corrector Primal Dual Interior Point Method Nonlinear Programming, Linear Programming, gradient method, interior point method Successive Quadratic Programming etc. are used for solving optimal reactive power dispatch problem [7,8]. These methods have to fail to handle due to non-convex, non-differential, non-linearity, multi-modal characteristic and nonsmoothness nature of the problem [5]. 
In Recent years, various evolutionary computation techniques like Optimization toolbox of MATLAB, cat swarm optimization, Gravitational Search Algorithm, Modified shuffled frog algorithm, Big Bang - Big Crunch (BB-BC) algorithm, differential Evolution, Strength Pareto Evolutionary Algorithm and Simulated Annealing etc. are able to solve all types of ORPD problems and these techniques do not required the objective function and type of the problem [8, $9,10]$. At present, researchers usually use aggregate method to deal with multi-objective reactive power optimization problem, namely, convert multi objective optimization problem to singleobjective optimization problem. The solution set can provide users the choice of diversification. This requires a compromise to get a satisfactory solution [1,2].

\section{Problem Formulation}

Optimal reactive power dispatch problem can be solved as a single objective optimization problem as well as multi objective optimization.

\subsection{Single Objective Optimization (SOO) Problem}

A single objective optimization problem is a problem in which only one objective function is considered at a time. Mathematical representation of SOO is defined as follows -

Min / maximization

$f(x)$

Subjected to

$$
\begin{aligned}
& \mathrm{g}_{\mathrm{i}}(\mathrm{x}) \leq 0 \quad \text { where } \mathrm{i}=1,2,3 \ldots . . \mathrm{i} \\
& h_{j}(x)=0 \quad \text { where } k=1,2,3 \ldots . . j
\end{aligned}
$$

Where $\mathrm{x}=\left(\mathrm{x}_{1}, \mathrm{x}_{2}, \mathrm{x}_{3} \ldots \ldots \mathrm{x}_{\mathrm{m}}\right)$ is a vector of $\mathrm{n}$ design decision variable.

$g i(x), h j(x)=$ inequality and equality constraints,

$I=$ index for inequality constraints.

$j=$ index for equality constraints,

$i$ and $j=$ number of inequality and equality constraints.

\subsection{Multi Objective Optimization (MOO) Problem}

Multi objective optimization problem is defined as follows-

$\begin{array}{lc}\text { Min / maximization } & \mathrm{F}(\mathrm{x})=[\mathrm{f} 1(\mathrm{x}), \mathrm{f} 2(\mathrm{x}), \mathrm{f} 3(\mathrm{x}) \ldots \ldots \mathrm{fk}(\mathrm{x})] \\ \text { Subjected to } & \mathrm{gi}(\mathrm{x}) \leq 0 \quad \text { where } \mathrm{i}=1,2,3 \ldots . \mathrm{i} \\ & \mathrm{hj}(\mathrm{x})=0 \quad \text { where } \mathrm{k}=1,2,3 \ldots \ldots \mathrm{j}\end{array}$

Where $[\mathrm{f} 1(\mathrm{x}), \mathrm{f} 2(\mathrm{x}), \mathrm{f} 3(\mathrm{x}) \ldots . . . \mathrm{fk}(\mathrm{x})]$ are the objective function.

\section{DESCRIPTION OF METHODS}

Numerous techniques have been proposed in the literature to solve the reactive power planning problem. They are categorized in to the following two groups [8] namely, conventional techniques and evolutionary computation techniques.

\subsection{Conventional Techniques}

Grudinin [11], proposed Successive Quadratic Programming (SQP) methods for solving a reactive power optimization model. To solve IEEE 30 bus and 278 bus system 6 optimization 
methods were used. Simulation results proved that the proposed SQP based approach was better than the SLP method.

Yan et.al [12], presented Predictor Corrector Primal Dual Interior Point Method (PCPDIPM) for solving the Optimal Reactive Power Flow (ORPF) problem. A new model of optimal reactive power flow in a rectangular form was proposed with the help of this method. In that model the Hessian matrices were constants and need to be evaluated only one time in the whole optimal process. Entire time required for PCPDIPM was always shorter than that for the traditional model for the 7 test cases.

Granville [13], proposed an Interior Point Method to solve the ORPD problem. This method was based on the primal dual logarithmic barrier method. The algorithm was tested on large power systems and 398.9 seconds CPU time was required. The proposed method has the following compensation: required less number of iterations or less number of control variables, robustness, no active set recognition problems and efficiency in dealing with optimal reactive power allotment and real power loss reduction problems in large scale and unhealthy network.

Lin et.al [14], proposed sequential quadratic programming to solve the OPF problem. The problem formulation was taken as integrated cost analysis and voltage stability analysis for competitive market. ORPD was establishing under a range of voltage stability margin desires in both normal and outage circumstances. The proposed method was demonstrated on IEEE 14-bus test system and the simulation result was compared with other methods.

Xiaoying et.al [15], proposed an Interior Point Branch and Cut Method for solving decoupled OPF problem. The Modern Interior Point Algorithm was used to solve Active Power suboptimal Problem and use IPBCM for solving linearization of Reactive Power Suboptimal Problem. The control variables and constraints of reactive power suboptimal problem were lesser than that of original OPF problem were the advantage of this method, it also improves the speed but this method fail to dealing with degenerate problem.

Alsac et.al [16], proposed linear programing was applied to the on-line reactive power rescheduling and optimal reactive power dispatch problem (ORPD) was formulated in a separable form. The main objectives of this paper were to minimize real power losses and the control variable for ORPD were for generator voltages, transformer taps etc.

This proposed method was used for on-line scheduling; the deviations from set points were minimized. A linear programing method was also suggested for solving non separable objective functions such as total real power loss. In this paper was also discussed that, mostly loss reduction occurs in the early iterations. The loss minimization has been achieved for three types of networks with 700, 1200 and 1330 buses in power system.

Torres et.al $[17,18]$, proposed the methods for calculate the price of reactive power support service in a multi-area power system. These methods were nonlinear convex network flow programming and cost-benefit analysis. With the help of several cost-benefit indexes, the reactive power maintains settlement regarding power rescue raises of tie lines were compute.

Pudjianto et.al [19] proposed linear programming and nonlinear programming for distributing reactive power between conflicting generators in a deregulated environment which was based on reactive OPF. It was concluded that by using LP method the total cost of the system which are associated with the requirement of reactive power was convincingly accurate. Whereas, nonlinear programming offer a more rapidly computation speed and precision for the solution but the convergence could not be guaranteed for every condition. 


\subsection{Evolutionary Computation Techniques}

Bhushan [20], proposed Differential Evolution (DE) algorithm for improves the voltage profile and simultaneously line loss reduction in power system. In this algorithm with the help of differential evolution optimal setting of Reactive power control variable were carried out. The proposed differential evolution algorithm was tested on three standard IEEE system and obtained satisfactory simulation result.

Suresh et.al [21], was proposed gravitational search algorithm (GSA) for solving optimal reactive power flow problem in a power system. This algorithm is used to reduce power losses and improves the voltage stability of the power system. This algorithm is also improving the economic operation of the system. Generator bus voltage magnitude, SVC controllers and transformer tap settings were the control variables for reactive power flow optimization. Gravitational search algorithm was a recently developed nature inspired algorithms for global optimization. GSA based algorithm was implemented on IEEE 30 bus test system and the results were compared with other algorithm and found superior results.

Kumara et.al [22], proposed cat swarm optimization (CSO) algorithm for optimal settings of RPD control variables. Cat swarm optimization algorithm was used for solving the multi-objective optimal reactive power dispatch problem in a power system. Model analysis of the system was used for static voltage stability assessment. The main objectives of this paper are to maximize of voltage stability margin and loss minimization. The control variables of this paper were Generator voltages, the capacitor banks and tap changing transformer settings. The proposed approach was examined and tested on the standard IEEE 30- bus test system.

Sakthivel et.al [23], proposed evolutionary programming algorithm was used to optimally position the FACTS devices. Real and reactive power optimization was necessary for economic operation and voltage security of power systems. This algorithm helps to improve power system condition by controlling the real power and reactive power dispatch. Real power generation was optimized by minimizing the fuel cost and real power loss was reduced to optimize reactive power dispatch. The low cost but fast respond thyristor controlled series capacitor (TCSC) and static VAR compensator (SVC) devices were used to achieve the objectives. Aggregate of generator bus voltages power generation, transformer tap settings and constraint locations of TCSC and SVC were taken as the control variables. The effectiveness of the proposed work was tested on IEEE-30 Bus test system and the results obtained were really encouraging.

Ankaliki et.al [24], proposed that paper to improve the voltage profile in distribution system by optimal reactive power maintain. It also helps in reduction of total real and reactive power loss of the power system thus resultant in reduction in energy loss of the system. Their effectiveness of the optimum reactive power support were show, the method was tested on 13-Bus Distribution System.

Lenin et.al [25], proposed a new search-acceleration parameter into the formulation of the original shuffled frog leaping (SFL) algorithm to create a modified form of the shuffled frog algorithm (MSFL) for solving reactive power dispatch problem. The formulation of this proposed algorithm is draws from other two techniques i.e. particle swarm optimization and shuffled complex evolution techniques. Shuffled frog leaping algorithm was used for solving the multiobjective reactive power dispatch problem in a power system. Modal analysis of the system was used for static voltage stability calculation. Reduce power losses and improve voltage stability margin were taken as the objectives. Generator voltages magnitude, tap changing transformer setting and reactive power generation of the capacitor banks were taken as the optimization variables. 
Anuradha et.al [26], proposed Optimization toolbox of Matlab for solving ORPD problem. Optimal Reactive Power Dispatch was required for power system control and proper operation. The main objective function of this paper was to minimize power system losses and improved the voltage profile and overall system operation. The control variables like switchable VAR sources, generator voltage magnitude, transformer tap-settings were used to solve ORPD problem.

The ORPD problem was taken as multi objective nonlinear constrained optimization problem with equality and inequality constraints The Optimization toolbox has been demonstrated on IEEE 30-bus system to solve multi objective optimization problem i.e. to minimize power losses and to reduce the voltage deviation and the obtained simulation results were compared with the differential evolution algorithm.

Duman et.al [27], proposed Gravitational Search Algorithm (GSA) for solving the optimal reactive power dispatch problem. The ORPD problem was formulated as a single-objective optimization problem and it also formulated as a non linear constrained problem. The aim of this paper real power loss and voltage deviations were to be minimized individually. This algorithm has been applied on IEEE 30 bus system consisting six generators and compared other algorithms reported those before in literature. Results showed that GSA was more efficient than others for solution of single-objective ORPD problem.

Sakthivel et.al [28], proposed Big Bang - Big Crunch (BB-BC) algorithm was used for solving the multi constrained optimal reactive power problem. The important tasks of this proposed algorithm were minimizing the real power loss and the voltage deviation at the same time. The presented algorithm ensures for protected operation and control of power system. The main advantages of this algorithm, it is free from large number of operators and this algorithm can be easily coded. The various decision variables were Generator voltage magnitude, transformer tap settings and static VAR compensators. BB-BC algorithm was tested on the standard IEEE-30 bus test system and the results were compared with other methods to prove the effectiveness of the new algorithm. The results were quite encouraging and the algorithm was found to be efficient.

Abido [29], proposed Strength Pareto Evolutionary Algorithm (SPEA) for solving ORPD problem. The optimal reactive power dispatch problem was formulated as a true multi objective optimization problem. The proposed algorithm solved the ORPD problem as a multi objective optimization problem where the real power loss and the voltage stability were minimized simultaneously. The simulation results verified the capability of the SPEA to make true and welldistributed Pareto optimal front solutions of the multi objective optimal reactive power dispatch problem in only one trail.

Tejaswini [30], proposed new meta-heuristic optimization algorithm, called Cuckoo Search algorithm, to solved the optimal reactive power dispatch (ORPD) problem. The main objective functions of this paper to minimize real power losses and to improve the voltage profile in a power system simultaneously. The optimal reactive power dispatch problem has been handled as a multi objective optimization problem while satisfying all security constraints. The evaluation shows the success and the advantage of the cuckoo search approach for solving ORPD problem. This algorithm has been demonstrated on standard IEEE 30 bus test system and the obtained simulation results were superior to differential evolution algorithm. 
Electrical and Electronics Engineering: An International Journal (ELELIJ) Vol 3, No 3, August 2014

\section{Summary of Different Methods Applied To Optimal Reactive POWER DisPatch PROBLEM}

Table 1 A Summary of Methods Which Are Considered In This Paper

\begin{tabular}{|c|c|c|c|}
\hline S. No & Reference No. & Objective function & Solution Method \\
\hline 1 & Grudinin [11] & Economical And Security & $\begin{array}{c}\text { Successive } \\
\text { Quadratic } \\
\text { Programming }\end{array}$ \\
\hline 2 & Wei Yan et.al [12] & $\begin{array}{c}\text { Reduce Power Losses, } \\
\text { Improvement Of Voltage Profile \& } \\
\text { Voltage Stability }\end{array}$ & $\begin{array}{l}\text { Predictor Corrector } \\
\text { Primal Dual Interior } \\
\text { Point Method }\end{array}$ \\
\hline 3 & $\begin{array}{c}\text { Sergio Granville } \\
\text { [13] }\end{array}$ & $\begin{array}{c}\text { Reduce Power Losses \& } \\
\text { Improvement Of Voltage Stability }\end{array}$ & $\begin{array}{l}\text { Interior Point } \\
\text { Method }\end{array}$ \\
\hline 4 & Lin et.al [14] & $\begin{array}{c}\text { Reduce Power Losses \& } \\
\text { Improvement Of Voltage Stability }\end{array}$ & $\begin{array}{c}\text { Sequential } \\
\text { Quadratic } \\
\text { Programming }\end{array}$ \\
\hline 5 & Xiaoying et.al [15] & $\begin{array}{c}\text { Fuel Cost, Reduce Real Power } \\
\text { Losses }\end{array}$ & $\begin{array}{c}\text { Interior Point } \\
\text { Branch And Cut } \\
\text { Method }\end{array}$ \\
\hline 6 & Alsac et.al [16] & $\begin{array}{c}\text { Reduce Power Losses \& } \\
\text { Improvement Of Voltage Profile }\end{array}$ & $\begin{array}{c}\text { Linear } \\
\text { Programming }\end{array}$ \\
\hline 7 & $\begin{array}{c}\text { Torres et.al [ } 17 \\
, 18]\end{array}$ & Cost & $\begin{array}{l}\text { Cost-Benefit } \\
\text { Analysis }\end{array}$ \\
\hline 8 & Pudjianto et.al [19] & Cost & $\begin{array}{l}\text { Interior Point } \\
\text { Method, Linear } \\
\text { Programming }\end{array}$ \\
\hline 9 & Bhushan [20] & $\begin{array}{c}\text { Reduce Power Losses \& } \\
\text { Improvement Of Voltage Profile }\end{array}$ & $\begin{array}{l}\text { Differential } \\
\text { Evolution }\end{array}$ \\
\hline 10 & Suresh et.al [21] & $\begin{array}{c}\text { Reduce Power Losses \& } \\
\text { Improvement Of Voltage Stability }\end{array}$ & $\begin{array}{l}\text { Gravitational Search } \\
\text { Algorithm }\end{array}$ \\
\hline 11 & Kumara et.al[22] & $\begin{array}{c}\text { Reduce Power Losses \& } \\
\text { Improvement Of Voltage Stability }\end{array}$ & $\begin{array}{l}\text { Cat Swarm } \\
\text { Optimization }\end{array}$ \\
\hline 12 & Sakthivel et.al [23] & $\begin{array}{c}\text { Fuel Cost, Reduce Real Power } \\
\text { Losses }\end{array}$ & $\begin{array}{l}\text { Evolutionary } \\
\text { Programming } \\
\text { Algorithm }\end{array}$ \\
\hline 13 & Ankaliki et.al [24] & $\begin{array}{c}\text { Reduce Power Losses \& } \\
\text { Improvement Of Voltage Profile }\end{array}$ & $\begin{array}{l}\text { Radial Distribution } \\
\text { System } \\
\end{array}$ \\
\hline 14 & Lenin et.al[25] & $\begin{array}{c}\text { Reduce Power Losses \& } \\
\text { Improvement Of Voltage Stability } \\
\text { Margin }\end{array}$ & $\begin{array}{l}\text { Modified Shuffled } \\
\text { Frog Algorithm }\end{array}$ \\
\hline 15 & $\begin{array}{c}\text { Anuradha et.al } \\
{[26]}\end{array}$ & $\begin{array}{c}\text { Reduce Power Losses \& } \\
\text { Improvement Of Voltage Profile }\end{array}$ & $\begin{array}{c}\text { Optimization } \\
\text { Toolbox Of Matlab }\end{array}$ \\
\hline 16 & Duman et.al [27] & $\begin{array}{c}\text { Reduce Power Losses \& Voltage } \\
\text { Deviation }\end{array}$ & $\begin{array}{l}\text { Gravitational Search } \\
\text { Algorithm }\end{array}$ \\
\hline 17 & Sakthivel et.al [28] & $\begin{array}{c}\text { Reduce Power Losses \& Voltage } \\
\text { Deviation }\end{array}$ & $\begin{array}{c}\text { Big Bang - Big } \\
\text { Crunch (BB-BC) } \\
\text { Algorithm }\end{array}$ \\
\hline 18 & Abido [29] & $\begin{array}{c}\text { Reduce Power Losses \& } \\
\text { Improvement Of Voltage Stability }\end{array}$ & $\begin{array}{l}\text { Strength Pareto } \\
\text { Evolutionary } \\
\text { Algorithm }\end{array}$ \\
\hline 19 & Tejaswini [30] & $\begin{array}{c}\text { Reduce Power Losses \& } \\
\text { Improvement Of Voltage Profile }\end{array}$ & $\begin{array}{l}\text { Cuckoo Search } \\
\text { Algorithm }\end{array}$ \\
\hline
\end{tabular}


Table 2 Comparison between conventional techniques and evolutionary computation techniques

\begin{tabular}{|c|c|c|c|}
\hline S. No & Object & Conventional Techniques & $\begin{array}{c}\text { Evolutionary } \\
\text { Computation Techniques }\end{array}$ \\
\hline 1 & Time & Less consuming & More consuming \\
\hline 2 & Accuracy & More accurate & $\begin{array}{c}\text { Less accurate as compare } \\
\text { to conventional techniques }\end{array}$ \\
\hline 3 & $\begin{array}{c}\text { Problem type and } \\
\text { problem nature }\end{array}$ & $\begin{array}{c}\text { Depend on type and nature of } \\
\text { the problem }\end{array}$ & $\begin{array}{c}\text { Does not Depend on type } \\
\text { and nature of the problem }\end{array}$ \\
\hline 4 & Parameter tuning & Less required & Is must \\
\hline 5 & Solution & Provide local optimum & $\begin{array}{c}\text { Provide near global } \\
\text { optimum }\end{array}$ \\
\hline
\end{tabular}

\section{CONCLuSiON}

The discussion shows the different methods involved in solving the optimal reactive power dispatch problems. The conventional techniques as well as evolutionary computation techniques based methods have been reported in literature for optimal reactive power dispatch problem. The conventional techniques methods are fast and accurate, but complex in nature whereas evolutionary computation techniques are easy to be applied, but time consuming and more parameter tuning required. In addition, Comparison between conventional techniques and evolutionary computation techniques are also discussed.

\section{ACKNOWLEDGEMENTS}

The authors sincerely thank her ME, Dissertation guide and the Director, MITS Gwalior, India to carried-out this research work.

\section{REFERENCES}

[1] Saied Salamat Sharif, "Optimal Reactive Power Flow Problem”, Msc Iran University of Science and Technology, Sept.1987.

[2] Congyu Zhang, Minyou Chen and Ciyong Luo, "A Multi-objective Optimization Method for Power System Reactive Power Dispatch", in proceedings of the Intelligent Control and Automation 28th World Congress, pp. 6-10, 2010.

[3] Altaf Q.H. Badar, B.S. Umre, A.S. Junghare "Reactive power control using dynamic Particle Swarm Optimization for real power loss minimization", International Journal of Electrical Power and Energy Systems, vol. 41, pp. 133-136, Oct 2012.

[4] Yong-jun Zhang, Zhen Ren "Real-time optimal reactive power dispatch using multi-agent technique", International Journal of Electric Power Systems Research, vol. 69, pp. 259-265, May 2004.

[5] A.A. Abou El Ela, M.A. Abido, S.R. Spea "Differential evolution algorithm for optimal reactive power dispatch", International Journal of Electric Power Systems Research, vol. 30, pp. 435-441, Oct. 2008.

[6] D. Godwin Immanue and Dr. C. Chritober Asir Rajan, "A Multi Objective Genetic Algorithm approach to Reactive Power and Voltage Control in Power System", International Journal of Research in Engineering and Technology, Vol. 2, pp. 174-178, 2013. 
[7] Tejaswini Sharma, Laxmi srivastava, "Evolutionary Computing Techniques for Optimal Reactive Power Dispatch: An Overview and Key Issues" in proceeding of Fourth International Conference on Communication Systems and Network Technologies (CSNT) IEEE, pp. 507- 511, April 2014.

[8] Chao-Rong Chen, Hang-Sheng Lee, Wenta Tsai "Optimal Reactive Power Planning Using Genetic Algorithm", in proceedings of the Systems, Man and Cybernetics, IEEE International Conference, vol. 6, pp. 5275-5279, Oct. 2006.

[9] Guanglin Cai, Zhen Ren and Tao Yu, "Optimal Reactive Power Dispatch Based on Modified Particle Swarm Optimization Considering Voltage Stability", in proceedings of the Power Engineering Society General Meeting, IEEE, pp. 1-5, 2007.

[10] Zhang Xuexia, Chen Weirong, P.N. Suganthan "Optimal Multi-objective Reactive Power Dispatch Considering Static Voltage Stability Based on Dynamic Multi-group Self-adaptive Differential Evolution Algorithm", in proceedings of the Intelligent System Design and Engineering Application (ISDEA),Second International Conference, pp. 1448- 1456, Jan. 2012.

[11] N. Grudinin, "Reactive power optimization using successive quadratic programming method", IEEE Trans. Power Syst., vol. 13, no. 4, pp. 1219-1225, Nov. 1998.

[12] Wei Yan, J. Yu, D. C. Yu and K. Bhattarai, "A new optimal reactive power flow model in rectangular form and its solution by predictor corrector primal dual interior point method", IEEE Trans. Power Syst., vol. 21, no. 1, pp, 61-67, Feb. 2006.

[13] S. Granville, "Optimal reactive dispatch through interior point methods", IEEE Trans. Power Syst., vol. 9, no. 1, pp. 136-146, Feb.1994.

[14] X. Lin, A. K. David and C. W. Yu, "Reactive power optimization with voltage stability consideration in power market systems", IEE proc.-Gener. Transm. Distrib., vol. 150, no. 3, pp. 305-310, May 2003.

[15] D.Xiaoying, W. Xifan, S. Yonghua and G.Jian, "The interior point branch and cut method for optimal power flow", 0-7803- 7459-2/02/\$17.00 @ 2002 IEEE, pp. 651-655.

[16] Alsac, O., J . Bright, M. Prais, B. Stott, "Further Developments in LP-Based Optimal Power Flow", IEEE Trans. on P WRS, Vol. 5, No. 3, -4ugust 1990, pp. 69'7-11 1.

[17] G. L. Torres and V. H. Quintana, "A jacobian smoothing nonlinear complementarity method for solving nonlinear optimal power flows", in Proc. Of 14th PSCC, Sevilla, Session 41, paper 1, June 2002, pp.1-7.

[18] Badrul H. Chowdhury, "Towards the concept of integrated security: optimal dispatch under static and dynamic security constraints”, Electric Power Syst. Research, vol.25, pp. 213-225, 1992.

[19] D. Pudjianto, S. Ahmed and G. Strbac, "Allocation of VAR support using LP and NLP based optimal power flows”, IEE proc.- Gener. Transm. Distrib, vol. 149, no. 4, pp. 377-383, July 2002.

[20] Bhushan Wane, "Optimization of reactive power for line loss reduction and voltage profile improvement using Differential Evolution Algorithm”, International Journal of Enhanced Research in Science Technology \& Engineering, Vol. 2 Issue 12, pp. 29-34, Dec. 2013.

[21] R.Suresh, C.Kumar, S.Sakthivel, S.Jaisiva, "Application of Gravitational Search Algorithm for Real Power Loss and Voltage Deviation Optimization”, International Journal of Engineering Science and Innovative Technology (IJESIT), Vol. 2, Issue 1, Jan. 2013.

[22] P.Surya kumari, Dr.P.Kantarao, "Power loss minimization using cat swarm optimization", International Journal of Application or Innovation in Engineering \& Management (IJAIEM), Vol. 2, Sept. 2013.

[23] S.Sakthivel, Dr.D.Mary, C.Ezhilan, "Global Voltage Stability Limit Improvement by Real and Reactive Power Optimization through Evolutionary Programming Algorithm”, International Journal Of Advanced Scientific And Technical Research, Vol. 1, Feb. 2012.

[24] Dr. Shekhappa G. Ankaliki, Prof. Sujata I. Katti , Dr. A. D. Kulkarni \& Dr. K. Thippeswamy, "Improvement of Voltage Profile and Reduction in Real \& Reactive Power Loss in Distribution System by Optimum Reactive Power Support", International Journal of Advances in Electrical and Electronics Engineering, Vol. 1, pp.243-250.

[25] K. Lenin , B.Ravindranath Reddy ,M.Surya Kalavathi, “ A Modified Shuffled Frog-Leaping Optimization Algorithm for Solving Optimal Reactive Power Dispatch Problem", International Electrical Engineering Journal (IEEJ), Vol. 4, No. 2, pp. 1049-1058, 2013.

[26] Anuradha Bhadouria, Dr. Laxmi Srivastava, "Optimal Reactive Power Dispatch Using The Matlab Optimization Toolbox", IJAIR, Vol. 2, pp.161-166, 2013.

[27] Serhat Duman, Yusuf Sonmez, Ugur Guvenc, Nuran Yorukeren "Application of Gravitational Search Algorithm for Optimal Reactive Power Dispatch Problem”, in proceedings of IEEE, pp. 519-523, 2011. 
[28] S. Sakthivel, M. Gayathri, V. Manimozhi, "A Nature Inspired Optimization Algorithm for Reactive Power Control in a Power System”, International Journal of Recent Technology and Engineering (IJRTE) ISSN: 2277-3878, Vol. 2, March 2013.

[29] M. A. Abido, "Multiobjective Optimal VAR Dispatch Using Strength Pareto Evolutionary Algorithm”, in proceedings of IEEE, pp.730- 736, 16-21, July 2006.

[30] Tejaswini Sharma, "Optimal Reactive Power Dispatch for Loss Reduction and Improvement of Voltage Profile Using Cuckoo Search Algorithm”, Journal of Innovative trends in Science, Pharmacy \& Technology, vol. 1, pp. 18-22, Jan. 2014

\section{Authors}

Tejaswini Sharma was born in Bulandshahr in UP, on September 22, 1990.Her graduation in Electrical and electronics Engineering from the Maa Kaila Devi Institute of Information technology and management in Gwalior and pursuing M.E at Madhav Institute of Technology and Science (MITS) in Gwalior. Tejaswini received honorary degree from institutions of RGPV University.

Alka Yadav was born in Dispur in Assam, on June 20, 1988.Her graduation in Electrical Engineering from the Maharana Pratap College of Technology (MPCT) in Gwalior and pursuing M.E at Madhav Institute of Technology and Science (MITS) in Gwalior. Alka received honorary degree from institutions of RGPV University.

Sangeeta Jamhoria was born on November 24, 1990. Her graduation in Electrical Engineering from the Maharana Pratap College of Technology (MPCT) in Gwalior and pursuing M.E at Madhav Institute of Technology and Science (MITS) in Gwalior.

Ritu Chaturvedi was born on January 08, 1991. Her graduation in Electrical Engineering from the Maharana Pratap College of Technology (MPCT) in Gwalior and pursuing M.E at Madhav Institute of Technology and Science (MITS) in Gwalior.
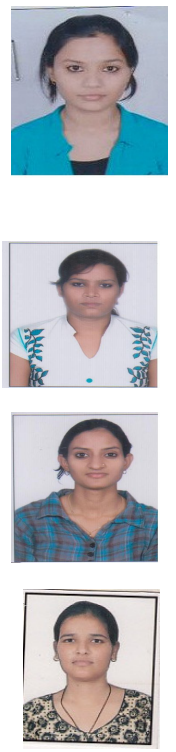